Fecha de recepción: diciembre 2017

Fecha de aceptación: marzo 2018

Versión final: julio 2019

\section{Transition Design: \\ Teaching and Learning}

Stacie Rohrbach ${ }^{\star}$ and Molly Steenson ${ }^{\star *}$

\begin{abstract}
Central to the development of Transition Design is its foundation in higher education. The theoretical basis that informs the practice of Transition Design develops from an emergent process comprised of hypotheses, theory, and testing in educational settings. These approaches - which focus on tackling specific, complex, placed-based challenges- must be tailored to address the nature of specific contexts and the varied learning of student cohorts and their respective needs. This paper argues the importance and thoughtful integration of Transition Design into design education and introduces curricula for undergraduate and doctoral design students. It outlines methods and tools that are utilized in our teaching, describes successes, identifies challenges, presents ideas for improvement, and proposes opportunities for development.
\end{abstract}

Key words: Transition Design - education - curricula - teaching - learning - theory - practice.

[Abstracts in spanish and portuguese at pages 262-263]

${ }^{*}$ Stacie Rohrbach is an associate professor and chair of Communication Design in the School of Design at Carnegie Mellon University. Her research investigates the design of learning experiences that aid the perception, processing, and understanding of complex, abstract information through concrete, experiential forms that sustain participant motivation and engagement. Rohrbach has garnered numerous grants for collaborative research projects, published papers, articles, and book chapters in international venues, serves on national design committees, and provides design pedagogy consultation nationwide. She holds an MDes in Graphic Design from North Carolina State University and a BFA in Graphic Design from Carnegie Mellon University.

${ }^{(*)}$ Molly Steenson is an associate professor in the School of Design at Carnegie Mellon University and leads the Doctorate in Design program. She is the author of Architectural Intelligence: How Designers and Architects Created the Digital Landscape (MIT Press, 2017). Dr. Steenson was an assistant professor in the School of Journalism and Mass Communication at the University of Wisconsin-Madison, adjunct faculty at Art Center College of Design in Pasadena, California, and associate professor at the Interaction Design Institute Ivrea in Italy. She holds a Ph.D. in architecture from Princeton University and a master's in architectural history (M.E.D.) from Yale University. 
Central to the development of Transition Design is its foundation in higher education. The theoretical basis that informs the practice of Transition Design developed from an emergent process comprised of hypotheses, theory, and testing in educational settings. These approaches -which focus on tackling specific, complex, placed-based challengesmust be tailored to address the nature of specific contexts and the varied prior learning of student cohorts and their respective needs. This paper argues the importance and thoughtful integration of Transition Design into design education and introduces curricula for undergraduate and doctoral design students. It outlines methods and tools that are utilized in our teaching, describes successes, identifies challenges, presents ideas for improvement, and proposes opportunities for development.

The kinds of thorny problems that Transition Design can address are all around us. They fall under the category of "wicked problems" that appear insurmountable because of their scale -poverty, incarceration, climate change, affordable housing, and gentrification, to name a few- whereas a tame problem can be solved easily by gathering the right information and plugging it into the problem. A wicked problem, on the other hand, can't be formulated in that manner because each one is a symptom of another problem. For example, as we write this article, a succession of hurricanes have hit several areas of the southern United States and Puerto Rico. Climate change is a contributing factor to the strength of these storms. Nonetheless, geographical, global, local, and political factors also play a role in the intensification of storms. Where do we begin to tackle the problem? Whatever we choose will be the symptom of another problem. For another example, the problems of high school completion rates, child poverty, incarceration, and affordable housing are all interconnected issues in a Pittsburgh African-American neighborhood. Where we attempt to intervene at the outset will have an impact on every other part of the equation. Indeed, the way that a wicked problem is defined "determines the nature of the problem's resolution" (Rittel \& Webber, 1973, p. 166).

In Transition Design, we acknowledge Rittel and Webber's argument that wicked problems are too complex to solve in the way that one approaches a "tame problem". Per their 1973 paper, "The formulation of a wicked problem is the problem! The process of formulating the problem and of conceiving a solution (or re-solution) are identical, since every specification of the problem is a specification of the direction in which a treatment is considered" (Rittel \& Webber, p. 161). There's no end, nor is there an "immediate and ultimate test of a solution" and "every solution... is a symptom of another problem" (p. 165). Also important in Transition Design education is the notion of "cosmopolitan localism" (Manzini, 2005), which situates itself in place-based practice that is nonetheless global in its exchange of information. We thus situate our teaching of Transition Design in contexts that are familiar to our students -where they live, study, and work- while encouraging them to consider the global ramifications of their actions.

As faculty members in the School of Design at Carnegie Mellon, we believe it is important to integrate Transition Design education into all levels of the curriculum and we have begun to heed this challenge. Our approaches to teaching a diverse body of students share a commitment to teaching them about the necessity of societal, systems-level change to address complex problems, the value of imagining and realizing sustainable futures, and the roles of designers in these processes. We present two vignettes in this article from 
either end of the spectrum that chronicle the lessons we are learning in teaching Transition Design. In particular, we will highlight the specificities of bringing Transition Design teaching and learning to bear at the undergraduate and at the doctoral levels. Above all, we want to emphasize that for us, as educators, Transition Design is a learning process, in which its curricular development and delivery furthers our inquiry and discovery.

\section{Part I: Teaching Transition Design in the Context of a Fourth-Year Undergraduate Design Research Studio}

Following two years of teaching Transition Design as a seminar in the graduate and doctoral programs in the School of Design where outcomes indicated its value, the faculty decided to integrate relevant content into an undergraduate senior design research studio that is currently being taught throughout the fall 2017 term. The planning, delivery, reflection, and revision of course activities illustrates the symbiotic relationship between teaching, research, and practice. Included is an overview of course themes that highlight methods and tools utilized, the successes of our approach that we've identified to date, challenges that have emerged in teaching Transition Design in the context of a senior design research studio, and our ideas for improvement.

\section{Overview of Course Methods and Tools}

In the context of a three-hour studio course that convenes twice a week over a 15 -week period, Associate Professors Stacie Rohrbach and Stuart Candy and Professor and Head of School Terry Irwin introduced 48 undergraduate design students to Transition Design theories and methods to foster long-term design thinking; the implications of current practices warrant careful consideration. Lectures, discussions, and activities served as a basis for grounding interventions designed for service and social innovation. At the onset of the course, students were introduced to wicked problems that exist throughout the Pittsburgh, Pennsylvania, area where they live and study. Configured into eight teams of six students, the cohort spent several weeks investigating issues that contribute to the lack of affordable housing and public transportation, gentrification, poor access to quality education and food, crime, and poor air and water quality in the region. In an attempt to move students through a series of steps that we identified as critical to the understanding of Transition Design, we utilized a range of methods and tools as outlined below.

\section{Framing Wicked Problems}

Diagramming root causes and consequences of place-based issues. The entry-point for the course focused on wicked problems that warranted systems-level change to address them effectively. Rooted in Transition Design, the course stressed the importance of tackling wicked problem because if they are left unaddressed, they may lead socio-technical systems in harmful directions. Students were shown familiar and foreign visual examples of various problems that related to each of their topics as a means of aiding the breadth and 
depth of their thinking at various levels of skill. The introductory lecture and discussion sought to help students gain insight into the characteristics, situatedness, and interconnectedness of wicked problems within the context of larger systems.

While gathering information on the topic assigned to their team, students were challenged to visualize the existing problems and outcomes that they discovered. Each team was given a printed panel on which to place their discoveries. The sheet included a diagramming framework that called for students to place their findings into high-level categories that are commonly used to delineate the root causes of wicked problems. The categories include social, technological, economical, environmental, and political (STEEP) issues (See Figure 1). The students were also tasked with identifying the root causes of issues and the consequences of current actions. To aid their thinking, the students learned about leverage points, which Donella Meadows describes as "places within a complex system (a corporation, an economy, a living body, a city, an ecosystem) where a small shift in one thing can produce big changes in everything" (1999).

\section{Mapping Stakeholder Relations}

Uncovering the fears/concerns, hopes/aspirations, and connectedness of stakeholders. The second stage of the course focused on worldview, which is characterized as the understanding of reality that people create based on their interpretation of prior experiences (Capra, 1983). People's worldviews describe and predict reality and thus shape how they perceive and engage in the world. Instead of continuing the mechanistic worldview that is common in Western culture and which exasperates capitalistic tendencies, the studio course described the value of a holistic worldview in tackling systems-level challenges (Capra, 1997). This change functions as a paradigm shift, which enables people to look at things in a new way. A few characteristics of this shift in perspective include relating instead of dominating, cooperating rather than competing, co-learning and re-skilling, and designing for long time horizons (Woodhouse, 1996). Holistic thinking encourages a speculative posture through which students are curious, pose questions, and emphasize relationships rather than simply aiming to solve problems and focusing on objects. In addition, a mindset that values waiting and observing is a critical component of this approach.

Any worldview causes people to believe what they see rather than identify their perceptions as pieces of reality. As a result, worldviews typically reinforce existing beliefs and expectations. Thus, the course called for students to define and investigate stakeholders related to their topics. Although the students didn't have access to specific stakeholders, we asked them to use the information they gathered to speculate on the fears and concerns and hopes and aspirations of those groups (See Figure 2). Each team chose three stakeholder groups related to their topic that represented a diverse set. They then performed triad mapping, which revealed points of affinity and opposition among the groups and the nature of the relationships among the groups (See Figure 3). 


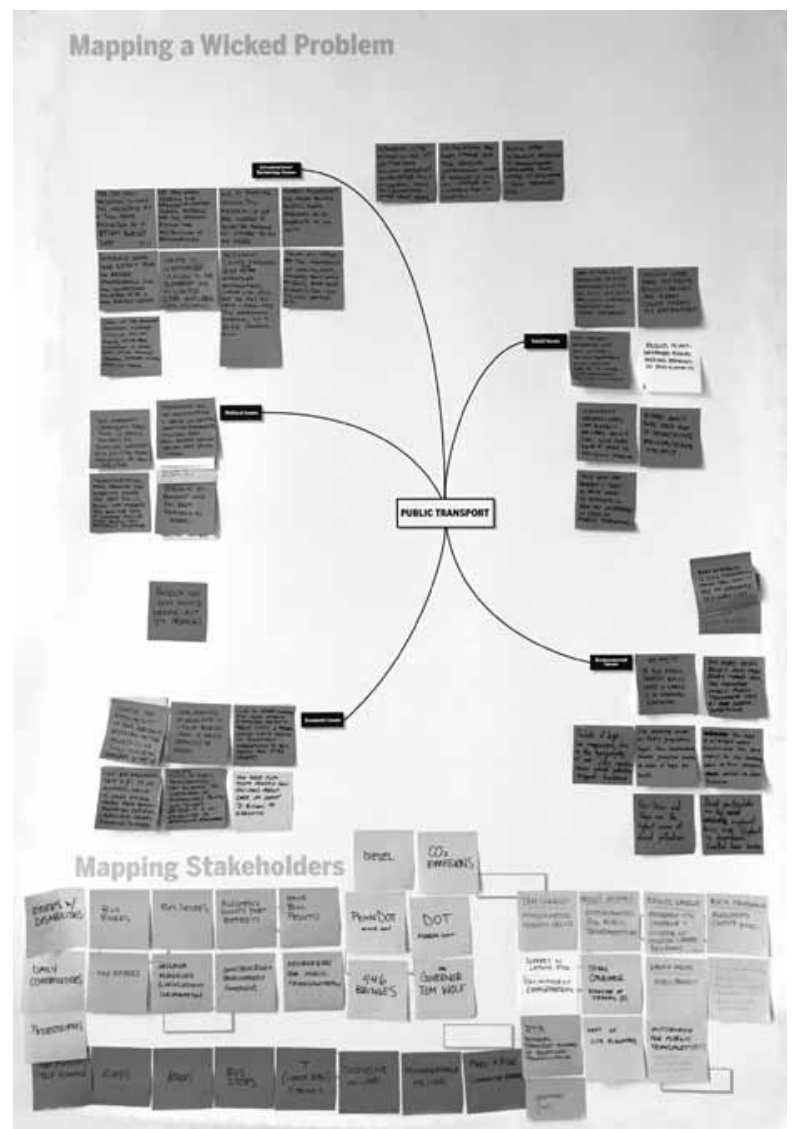

Figure 1. Students used social, technological, economical, environmental, and political categories to delineate the root causes of transportation problems in Pittsburgh. Figure 2. Students described the fears/concerns and hopes/ aspirations of air quality stakeholders in Pittsburgh.

Figure 1.

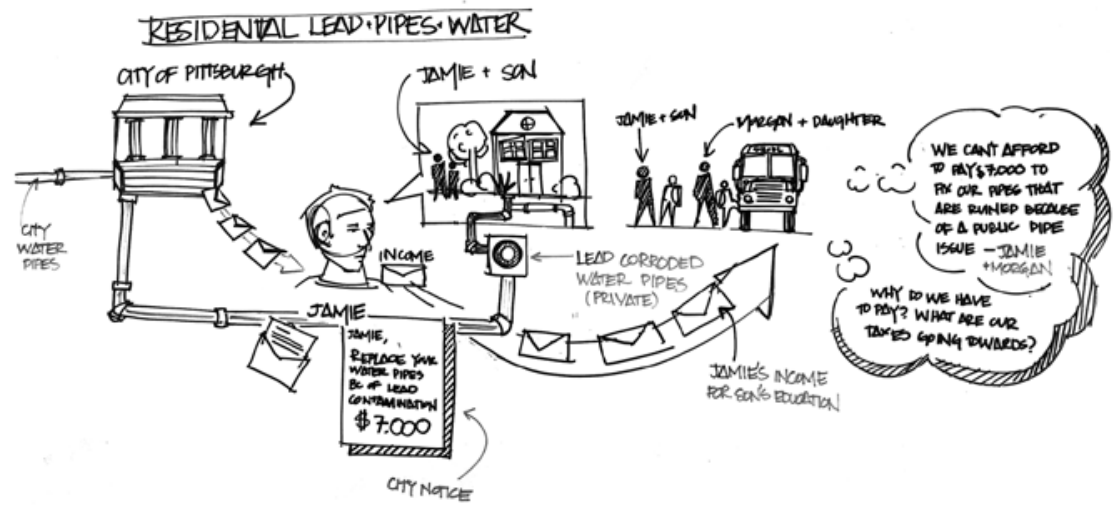

Figure 2. 


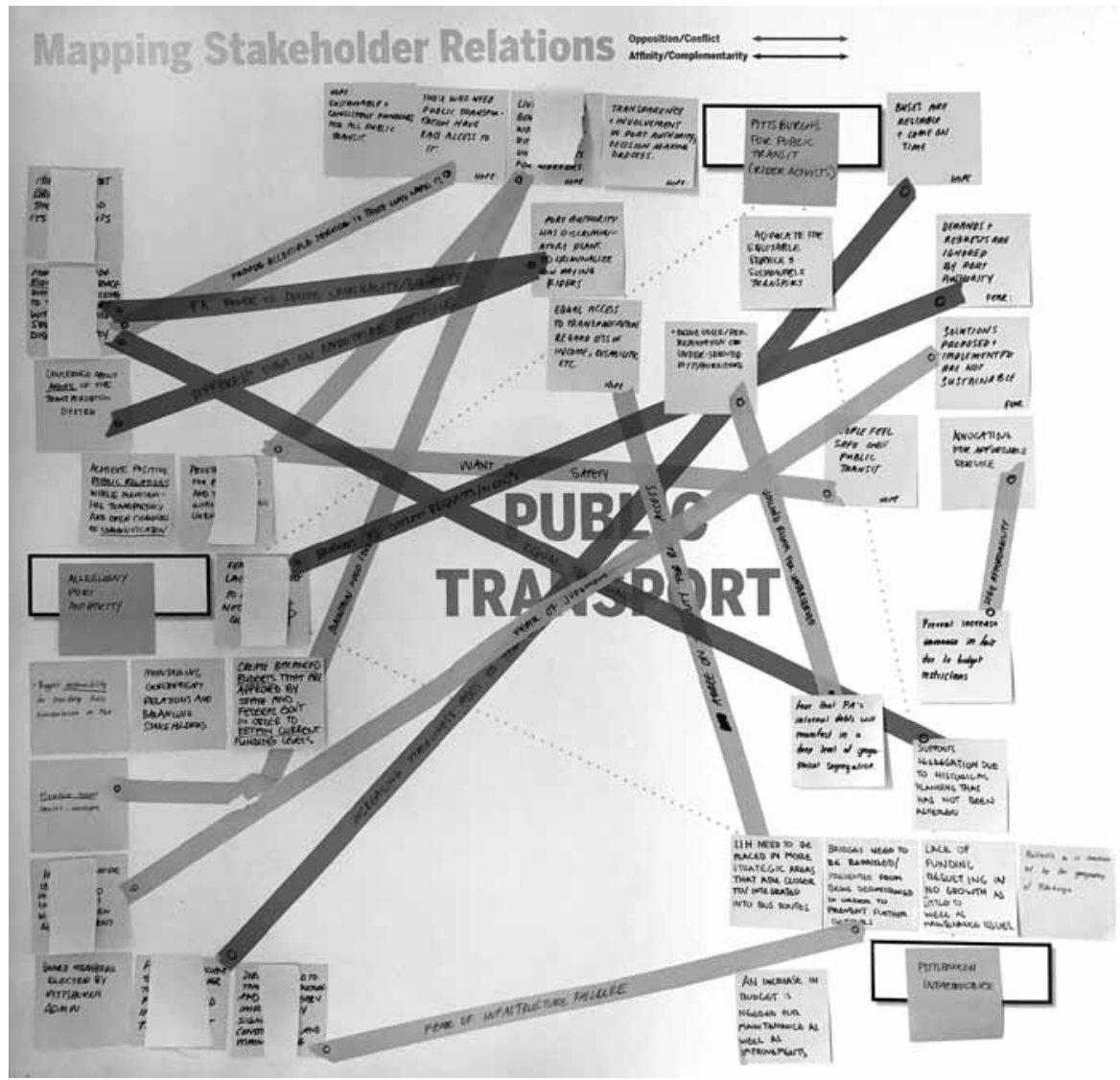

Figure 3. Students performed triad mapping, which revealed points of affinity and opposition among stakeholder groups, and the nature of their relationships. 


\section{Developing Visions}

Defining short-, medium-, and long-term futures. Once the students had gained a fair understanding of the challenges that they faced at various levels of scale and started to consider the many stakeholder groups involved, the studio shifted their attention to speculating on futures as a means of exploring diverse ways of sense making. Note that 'futures' is plural because, in contrast to the past, which is singularly defined, futures do not yet exist and thus can take many different paths. Informed by a method in course instructor Stuart Candy's dissertation (2010), students conducted an exercise that aided their development of possible, probable, and preferable futures. Relative to the full set of topics, they brainstormed what could happen, what was likely to happen, and what they preferred to happen. To aid their thinking, students were provided with a template to frame the definitions of their futures in relation to social (S), technological (T), economical (Ec), Environmental (En), and Political (P) concerns. In addition to the STEEP framework, the eight teams were combined into four pairs and provided with a lens through which to view their futures. The lenses included growth (progress has continued), collapse (society has come apart), discipline (order is coordinated or imposed), and transform (a profound historical evolution occurred). After generating characteristics of Pittsburgh in 2050, the students developed written scenarios that served as a hypothetical history (See Figure 4). In subsequent class sessions, students were encouraged to drill down through levels of scale to explore their futures in greater granularity and think more deeply about the scenarios they developed. Focusing specifically on their topics, the student teams collaboratively created a vision for the year 2050 in which the current problem they had been studying no longer exists. In this exercise, students were urged to consider granular aspects of the situation. Once again, the students developed a written story to convey their thinking. A few teams also visualized designed objects and services that existed in their vision of 2050 as a means of clarifying their ideas and aiding their writing (See Figure 5). Next, students were introduced to "Seeing in Multiple Horizons: Connecting Futures to Strategy" (Curry \& Hodgson, 2008), which aims to assist students in their thinking of short-, medium-, and long-term change. The framework also strives to facilitate "cultural transformation and aid innovative exploration and wise action in the face of uncertainty and not-knowing" (Wahl, 2017). The framework consists of three horizon lines that move from present day to a future time. One horizon sustains innovation as the status quo. A second horizon disrupts the systems and changes what is possible. A third horizon involves a transformation that moves the system towards a regenerative culture. Wahl (2017) explains, "Three Horizons thinking offers a methodology and practice of seeing things from multiple perspectives and valuing the contribution that each perspective makes to the way we bring forth the world together" (p. 1). The students used the three horizons to define milestones along a timeline that led to the vision they defined. They described the milestones that occurred over a thirty-year period of time using text and images. Their speculations served as the first steps in defining design opportunities that are situated within larger systems (See Figures 6 and 7). 
Figure 4. Students explored alternative futures by mapping social, technological, economic, environmental, and political issues through grow, collapse, discipline, and transform lenses.

Figure 5. Students visualized designed objects and services that existed in their vision of 2050 as a means of clarifying their ideas and aiding their writing.

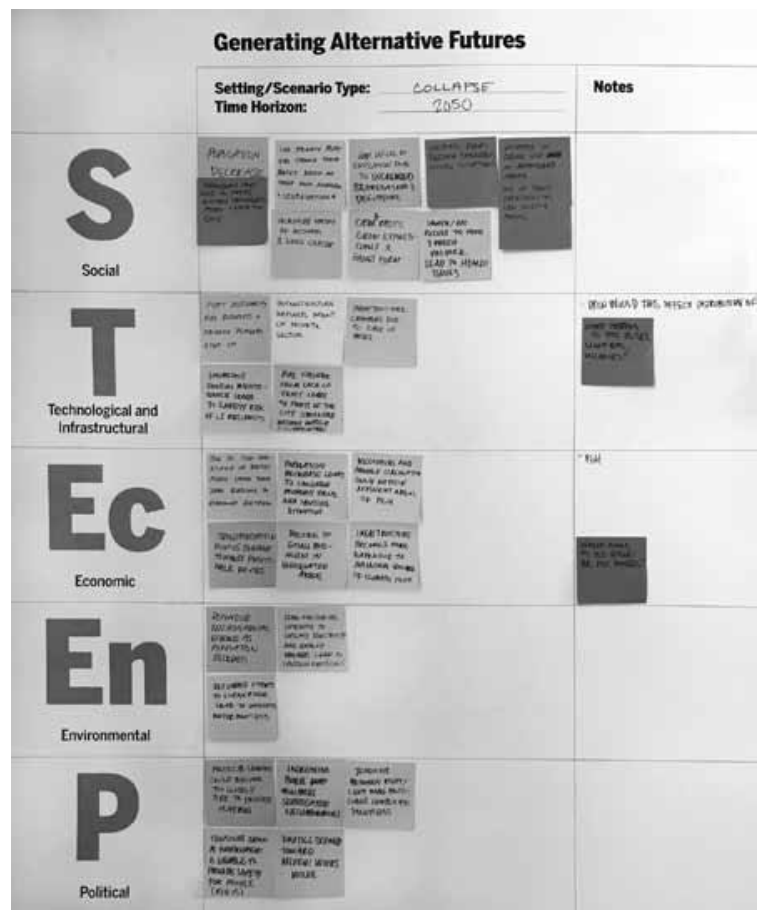

Figure 4 .

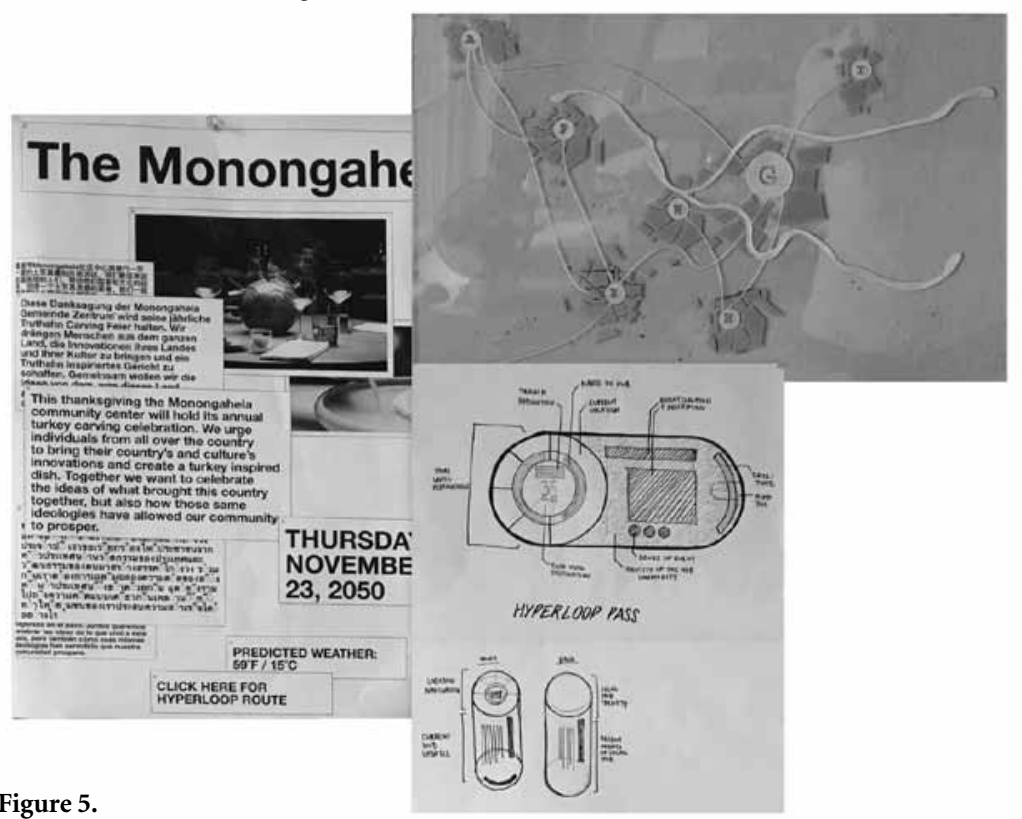




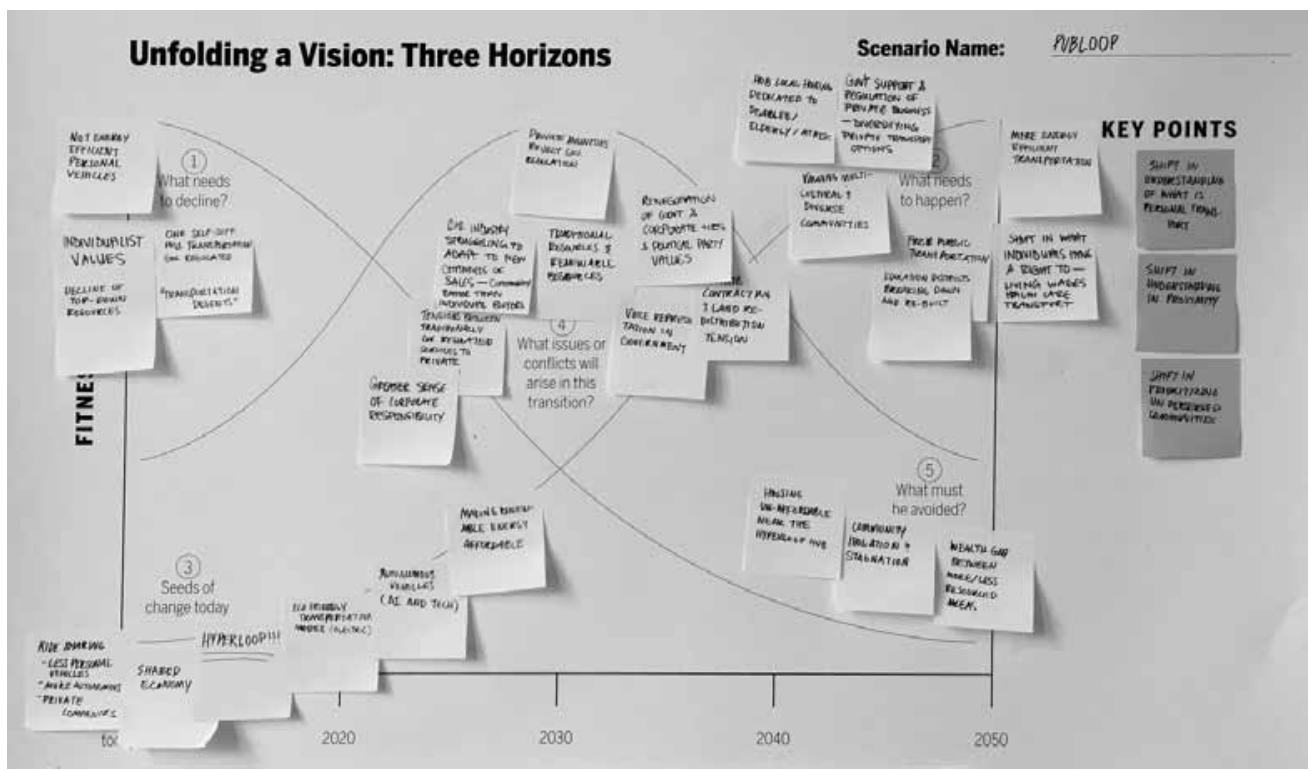

Figure 6.

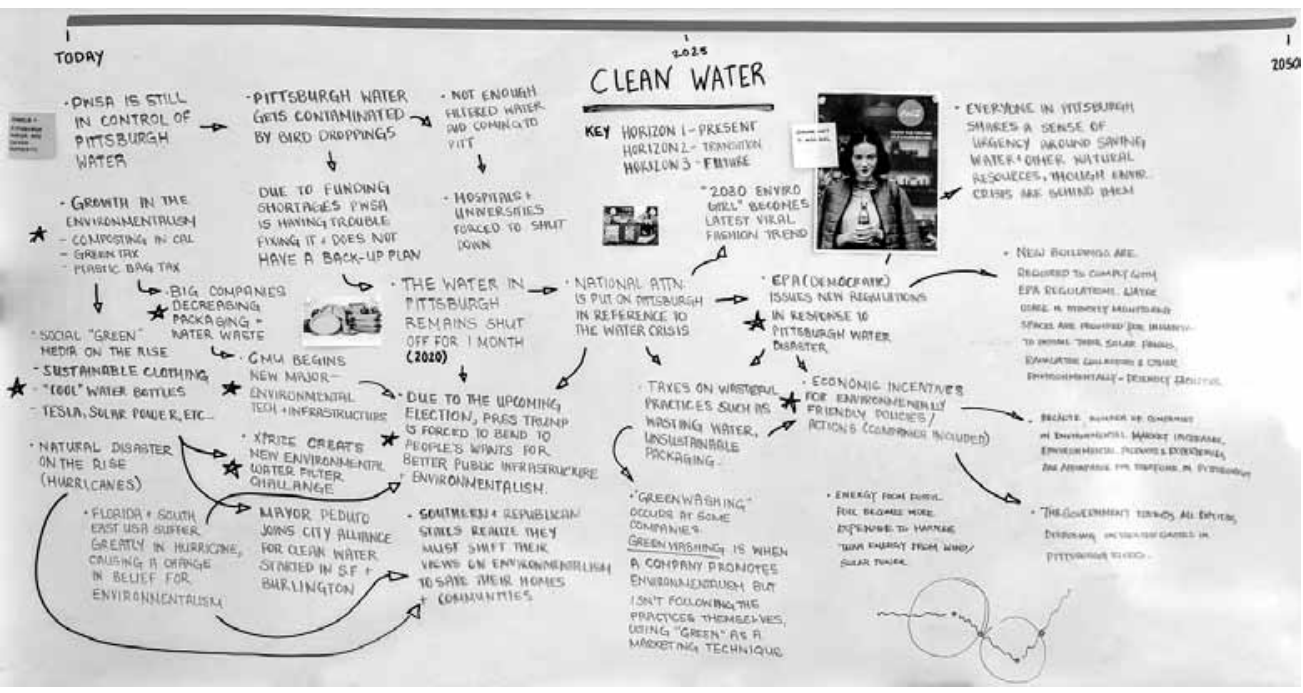

Figure 7

Figure 7. Students used the three horizons to define milestones along a timeline that led to the vision they defined. Figure 6. Students used the three horizons framework to see their ideas from multiple perspectives and identify the value of each contribution. 


\section{Exploring Theories of Change}

Describing the satisfaction of human needs through design. Given that the course focused on teaching approaches that aid students' thoughtful design of products, communications, and environments, we discussed human needs as guiding this process. Chilean development economist Manfred Max-Neef (1991) published a taxonomy that proposes a theory for the classification of human needs. He argues that circumstances cause people to take action in response to a fundamental need and that people are motivated by the same set of nine needs -subsistence, protection, affection, understanding, participation, idleness, creation, identity, and freedom- but the ways in which they satisfy them are unique and infinite. For example, in order to satisfy a need for subsistence, people may be motivated to get something to eat. It is important to note that not all satisfiers address needs in a sustainable manner. Some satisfiers address a single need, stimulate a false sense of satisfying, and/or inhibit satisfaction or destroy the possibility of satisfaction. Students used Max-Neef's taxonomy as a tool for studying how the design of existing products, communications, environments, and services satisfies or inhibits fundamental human needs. They defined and explored a design piece that they interact with often and another that they believed included few or no inhibiting satisfiers (See Figures 8, 9, and 10). The class discussion that followed illustrated the difficulty in finding something that had been designed by humans that was void of inhibiting satisfiers.

Having defined aligned futures that exist along a timeline and investigated human needs, the students were poised to consider the role that lifestyles play in setting the context for an exploration of design interventions. They turned their attention to everyday life, as examining people's actions provides insight into how they satisfy their fundamental human needs. Students were asked to think about the level of control that communities retain in satisfying their needs in the past and in the present day. They learned that as centralized institutions such as government, corporations, media, and police increase their control of satisfying human needs, life becomes more homogenous, fragmented, and lifeless. This transfer of control can cause ecological, social, economic, and political problems as the function and structure of everyday life is altered (Kossoff, Tonkinwise, \& Irwin, 2015). In order to regain control of satisfying human needs, students were encouraged to consider the benefits of cosmopolitan localism, where communities are human-scaled and place-based in their activities yet exchange information globally (Irwin, 2015). Students examined everyday life at various levels of scale as a means of understanding the nestedness of community relationships, helping them to grasp a larger vision of what sustainable communities in Pittsburgh might look like. 


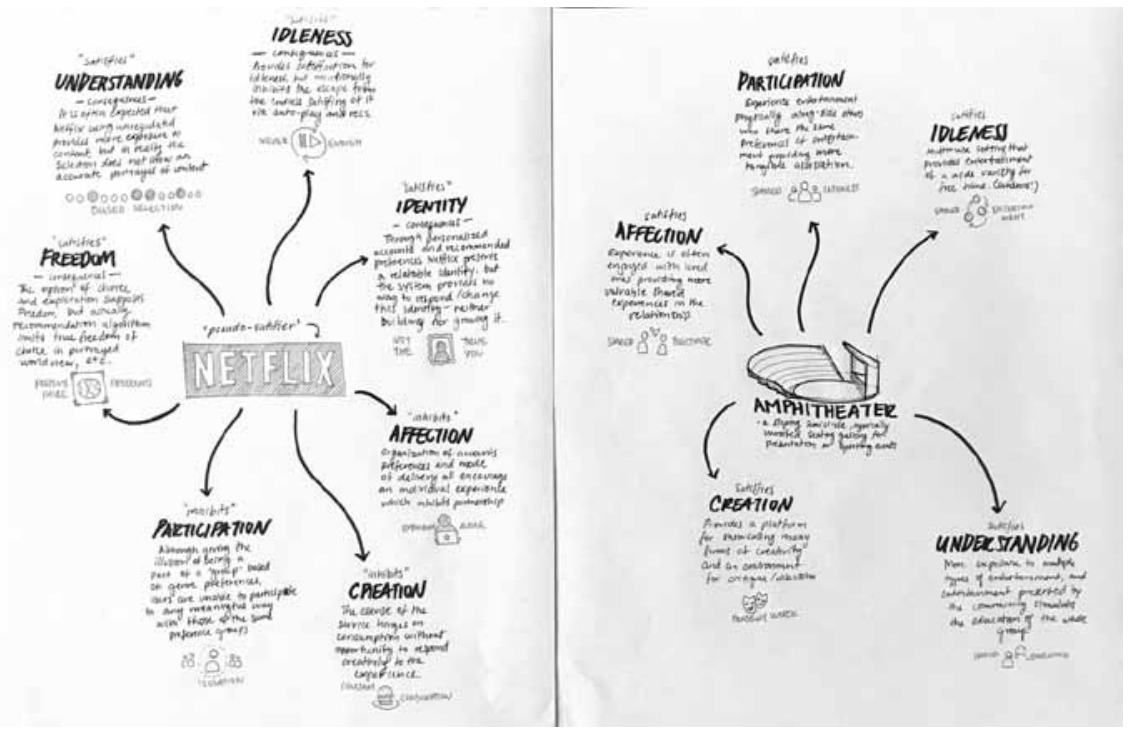

Figure 8.

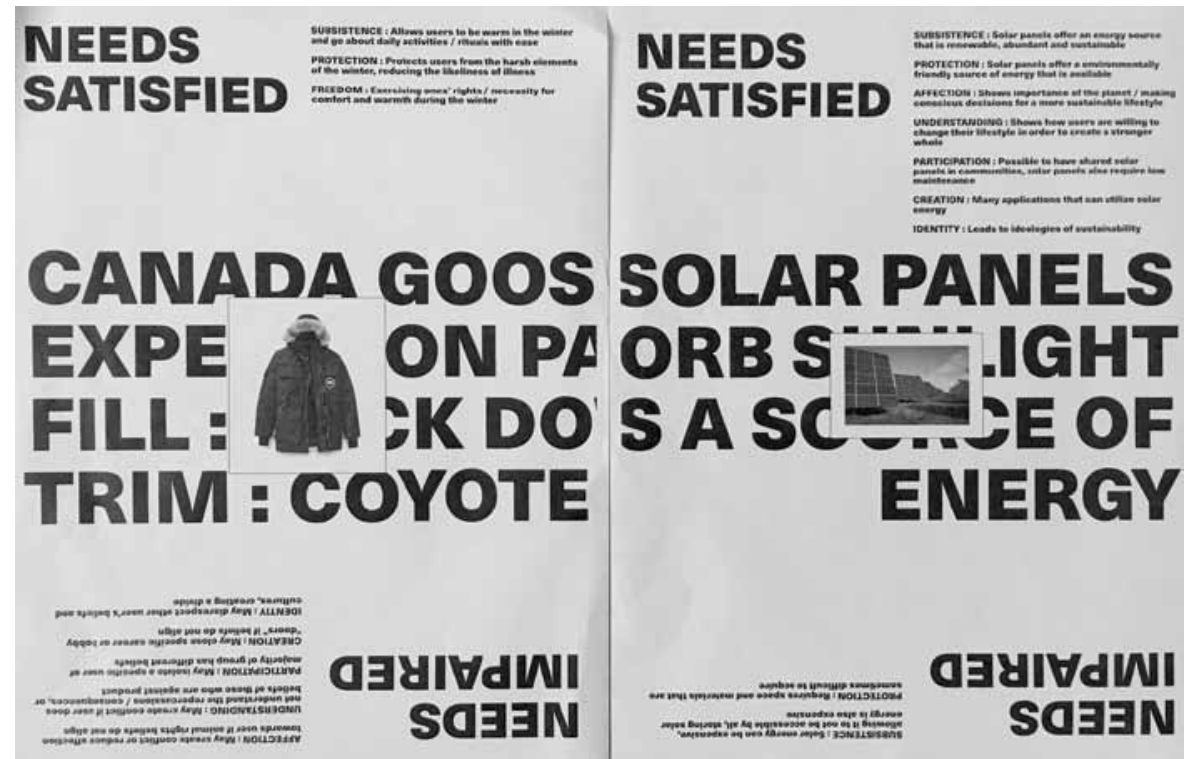

Figure 9.

Figure 8. Students investigated designed communications, products, environments, and services, learning how they satisfy or inhibit the satisfaction of human needs. Figure 9. Students investigated designed communications, products, environments, and services, learning how they satisfy or inhibit the satisfaction of human needs. 


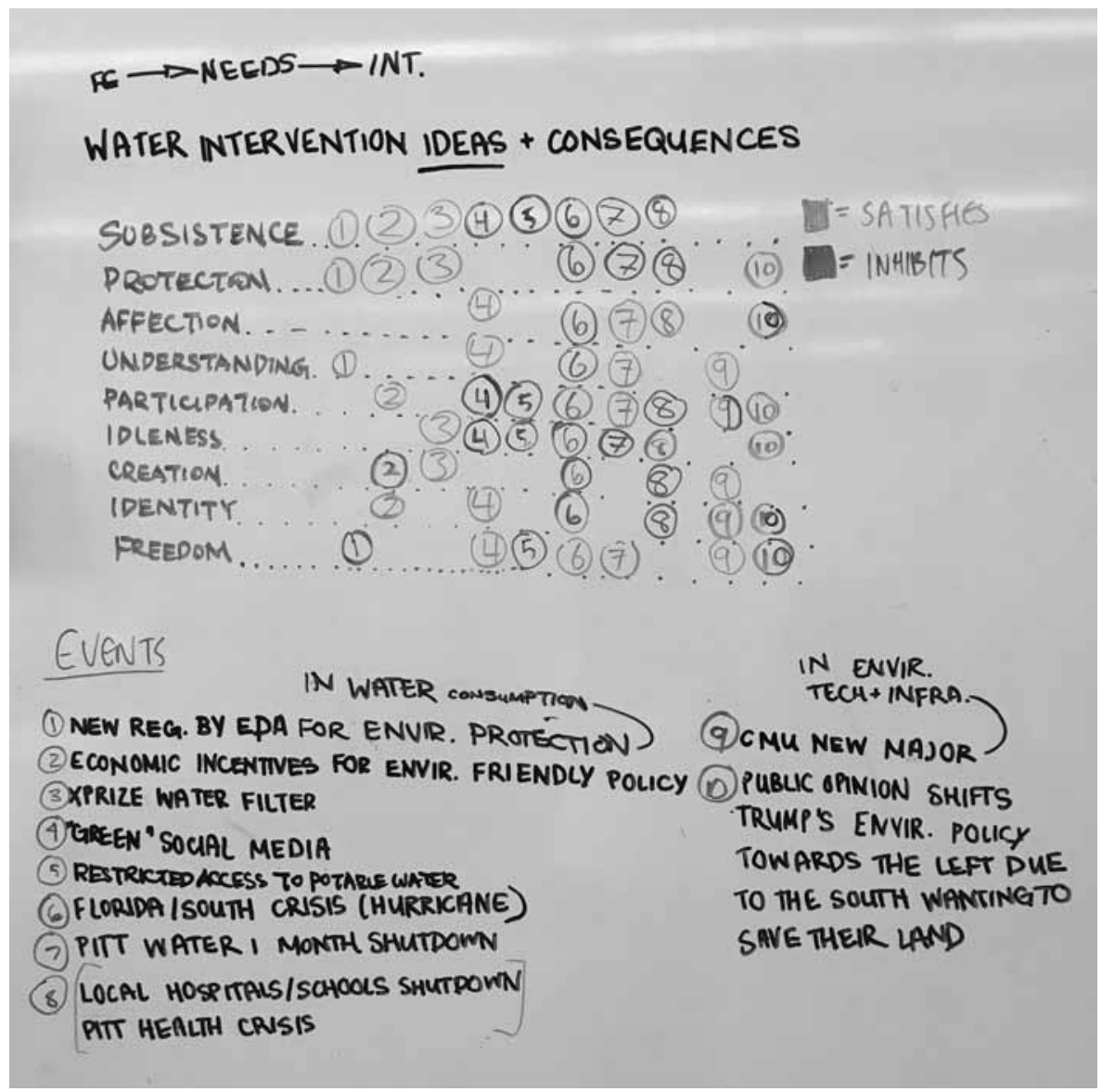

Figure 10. Students reviewed their ideas for possible design interventions, identifying how they satisfy or inhibit the satisfaction of human needs.

\section{Defining Design Interventions}

Proposing opportunities for design to seed and catalyze systems-level change. In an effort to help students build on the Transition Design work that they conducted, and aid their realization of design opportunities for intervening in Pittsburgh systems in appropriate and effective ways, we introduced them to service design and design for social innovation concepts. The students gained an understanding of the characteristics that define these areas of design focus and learned fundamental approaches that enable their practice. 
Relative to service design, the students explored the value of fostering relationships between customers and service providers to improve the quality of their interactions and the service that is rendered. Associate Professor Molly Wright Steenson, who holds expertise in service design, led a session in music sharing. They quickly brainstormed service scenarios and prototyped concepts for presentation to the class. This fast-paced activity, a microscopic version of the Global Service Jam (Thomas \& Leber, 2016), encouraged students to utilize the design skills they had learned and acquired over the past three years of their undergraduate design studies (See Figure 11).

Throughout the following week, students dove into design for social innovation under the advisement of Cheryl Dahle, CEO of Flip Labs and a distinguished Adjunct of Professional Practice in the School of Design at Carnegie Mellon. She referred to the article "Rediscovering Social Innovation" in defining the key tenets of design for social innovation as "a novel solution to a social problem that is more effective, efficient, sustainable, or just than existing solutions and for which the value created accrues primarily to society as a whole rather than private individuals" (Phills, Jr., Deiglmeier, \& Miller, 2008), and she introduced students to a range of relevant businesses, services, and products, such as fair trade and a human-powered washing machine. We framed such social innovation interventions as components of Transition Design because collectively, they can lead to longer-term systems change. After the class took students through a social innovation case study that focused on the fisheries in Indonesia and highlighted important characteristics and considerations of the situation, Dahle showed students a four-quadrant framework aimed at helping them define the projected outcomes of intervention proposals. One axis focused on the scale of impact, while the other mapped the complexity of the concept. The students then used the social design pathways to "see that broad terrain; to identify the skills required for action; to identify the kinds of partners needed for success; to preview the scales of engagement; and to foresee the possible impacts of social design projects" (2017). In this framework, one axis focused on the scale of engagement while the other asked students to consider the range of expertise of parties involved (See Figure 12).

Once the students had brainstormed design interventions through service design and design for social innovation lenses (See Figure 13) that aligned with the futures timelines they created, they conducted an exercise that is currently leading them to take action on their thinking and bring an intervention to fruition. First, each student team chose six intervention ideas to pursue. Next, every student committed to an interest in carrying a few of the interventions further during the remainder of the term, assigning to them learning goals in conducting each study. Having defined their objectives, the teams mapped possible connections between their intervention ideas and the other topics being investigated by their classmates. This step illuminated the nestedness of class topics and opened doors for collaboration among the cohort. As a result, the class cohort reconfigured itself into new teams that included three or four members whose research during the first half of the term and design skills poised them to tackle their chosen intervention. The new teams then defined existing obstacles and proposed ways of addressing them with the resources they had at hand. Throughout the next six weeks, the student teams developed their interventions as hypotheses that they could use to receive school-wide feedback at the close of the term (See Figure 14). 
Figure 11. Students quickly brainstormed service scenarios and prototyped concepts for presentation to the class.

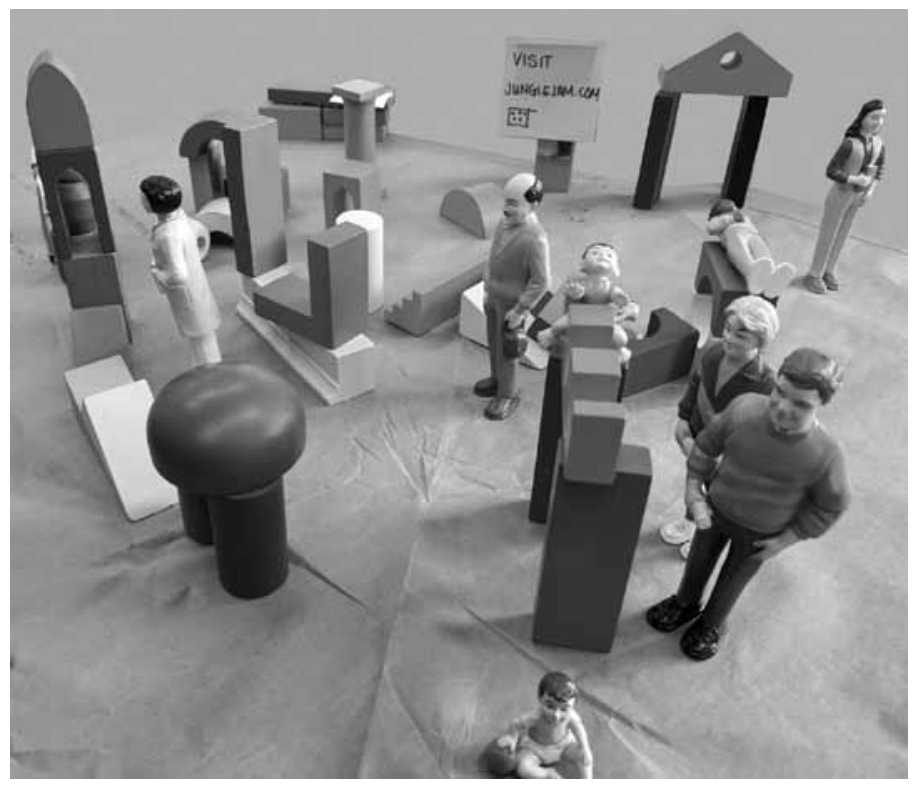

Figure 12. Students used the social design pathways framework to foresee the possible impacts of their intervention ideas, identify scales of engagement, and propose partners.

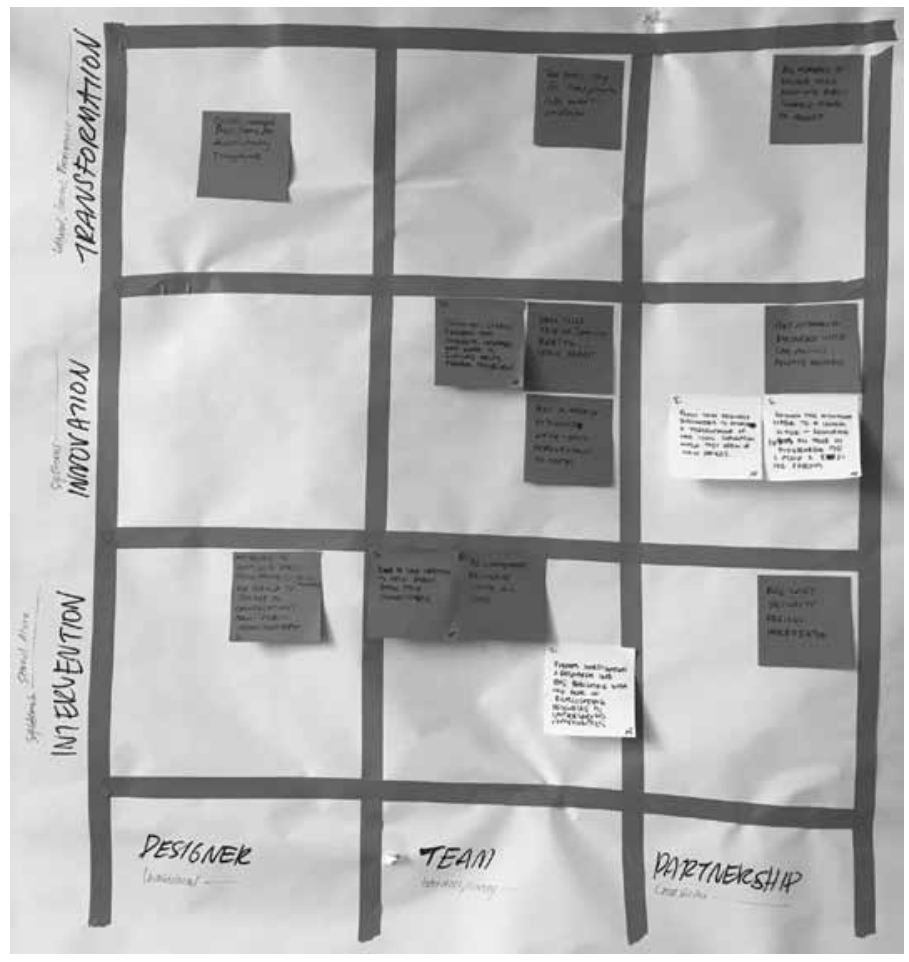



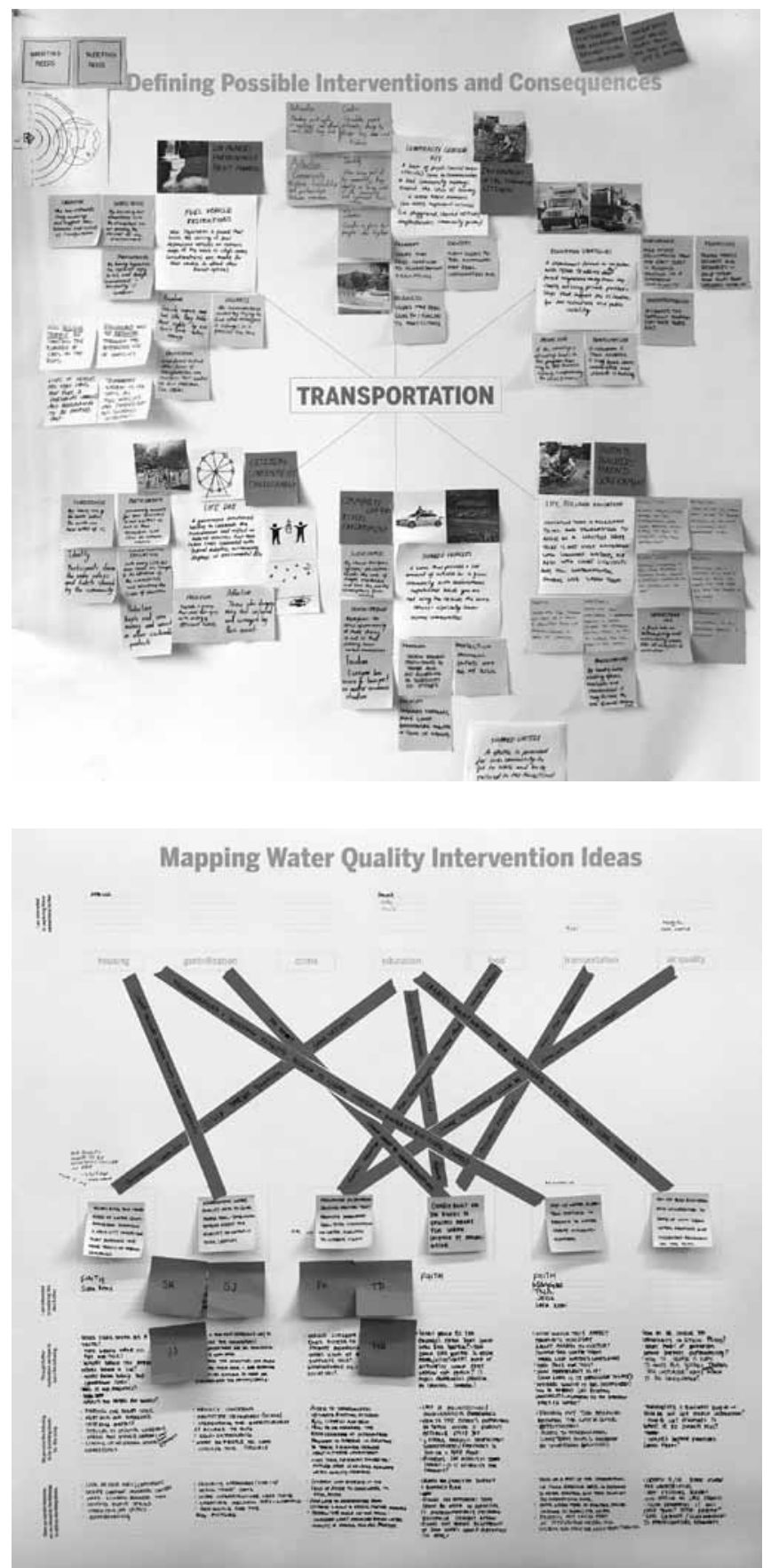

Figure 13. Students mapped their service design and design for social innovation intervention ideas that they believe have significant merit, in concert.
Figure 14. Students teams mapped possible connections between their intervention ideas and the other topics being investigated by their classmates, articulated research questions, and proposed plans for working through known obstacles. 


\section{Successes}

Despite common challenges that arise when developing and delivering a new course, we were pleased to see the students' incremental growth throughout the term. Our interactions with them highlighted successes in our approach to teaching Transition Design in the context of the design research studio -some of which were aspirational, while others were unanticipated.

Students grasped the facets of wicked problems and explored how to enter them. Understanding that wicked problems are systems problems that reside within other systems enabled students to shift their thinking from solving small-scale, immediate problems to seeing relationships among their topics at various levels of scale. By working through a series of exercises, students illustrated a confidence in defining and tackling manageable facets of wicked problems rather than simply becoming overwhelmed and paralyzed by their magnitude. They also learned to distinguish consequences of wicked problems by tracing their root causes up through levels of the systems. Starting the course with systems-thinking discussions and activities led students to alter their views of local challenges and appropriate ways of intervening. A quote popularly attributed to Albert Einstein states, "No problem can be solved by the same kind of thinking that created it". Given that systems are so ubiquitous that they often go unnoticed, the curriculum helped students to identify nested systems, as gaining the skills to define them is critical to the study and practice of Transition Design.

Students recognized the importance of stakeholders in the Transition Design process. Although this task proved to be difficult, the students began to indicate awareness of the connectedness of their topics and stakeholders, an appreciation for the complexity of the challenges they studied, and a cognizance of how little they knew about their stakeholder groups. Course activities caused the students to recognize pitfalls in stereotyping stakeholders and the importance of working directly with stakeholder groups. As the semester transpired, the students also expressed a deep appreciation for the research that their peers had conducted on adjacent topics.

Students created visions of futures that informed their design actions in the present. After participating in several sessions that focused on envisioning futures, the students exhibited strength in working in a state of uncertainty. Course activities taught students how to toggle between short- and long-term thinking and the longstanding consequences of what they design. As a result, interactions with students indicated that they had developed mindfulness for futures when intervening in the present. The students also noted that this course connected well to design studies courses that they had taken in prior years that focused on cultures, systems, and futures. They explained that these courses helped them see salient points in their learning of Transition Design and apply the knowledge and skills that they had acquired over several years to real-world challenges in meaningful ways.

Students learned the value of satisfying the needs of all living things through design. Given that class activities and discussions included mindfulness for all living things, students intuitively adopted a living-centered, rather than human-centered approach for design. In 
fact, when introduced to Manfred Max-Neef's categorization of human needs (1991), students promptly pushed back, explaining the framework's lack of inclusiveness relative to all living things. Nonetheless, his theory served as a tool that helped students understand how design satisfies or inhibits a range of human needs. Through their analysis and proposal of designed products, communications, environments, and services, students also demonstrated a realization of the value of helping communities control the satisfaction of their human needs at a local level.

Students assembled a toolkit that aids their own proposals for design interventions. Next, in order to move beyond theoretical discussions of large, long-term systems change, students took the methods and approaches that they learned throughout the course and applied them to the design of interventions in the present day. Instead of seeing insurmountable design challenges, they demonstrated strengths in articulating the characteristics of specific situations and suggesting appropriate methods and tools to investigate and move through the problems. As a result, they exhibited confidence and agility in tackling ambiguous challenges rooted in service design and design for social innovation, which often reside within the larger umbrella of Transition Design.

Students developed a mindfulness for their actions and experienced a mindset shift. Through several weeks of intense work sessions with their group of peers, students started to recognize collaboration as a critical component of Transition Design, which they practiced and advocated. Plus, although the process was vastly different than what they experienced in the past, the students indicated an understanding of the value of designing a series of "interventions" over a long period of time instead of "solutions" that existed solely in the present. Their approaches often took a "less is more" approach to design, illustrating a soft hand in intervening. By the middle of the term, students were able to describe the potential impact design could have in seeding and catalyzing positive change in the world and accepted important responsibilities in leading these efforts.

\section{Challenges}

Given that fall 2017 marked the first delivery of the Design Research Studio, the instructors spent several months prior to the term carefully planning the course. Nonetheless, its development was based on lessons learned through the investigation and development of Transition Design theories, workshops, and a graduate seminar course that had been previously conducted. The differences in the course structure, its duration, and the nature of the cohort caused new challenges to arise for us to address.

The structure and format of the course wasn't always conducive to the type of learning necessary. Early in the course, students recognized the importance of working with stakeholders, as they lacked a genuine understanding of stakeholders' concerns and aspirations. Nonetheless, as instructors, we firmly believe we have an ethical responsibility to do no harm. In design education, we often follow a practice of gathering information from stakeholders in local communities for short-term studies that is often devoid of symbi- 
otic exchange. This approach to research runs the risk of causing participants to become disenfranchised from the process as their engagement fails to lead to improvements in their communities due to the short duration of the projects. We chose not to contribute to this problem, which in turn led to challenges in the classroom. As we expected, students struggled to work within a hypothetical context. They expressed discomfort in basing design proposals on the limited information they gathered about stakeholders and sought to validate or negate their design interventions in realistic settings.

Although students stated an appreciation for the content of the course, they explained the difficulty in it being structured as a survey of approaches and methods. The students were gaining exposure to a broad range of topics that are critical to the study and practice of Transition Design. However, the course lacked ample time to frequently engage students in rich conversations that aided their deep understanding of the topics covered. As a result, the students expressed frustration in not fully grasping the relevance of the course content to their immediate practice of design.

The course sometimes failed to situate students' learning within a broad and critical design context. Many of the class sessions consisted of short lectures and discussions, followed by exercises that aimed to solidify students' learning of course concepts. Although the fastpaced nature of the described format enabled us to cover a lot of information and sustain student engagement, it also frequently caused students to lose sight of the big picture, as we did not continually situate their incremental knowledge and skill acquisition in the context of a larger whole grounded in Transition Design.

The students also noted an appreciation for specific approaches introduced in the course but questioned how opposing theories may function. They sought comparisons that would prevent them from making ill-informed design decisions. Given the short duration of the course and the amount of information we aimed to cover, we chose to narrow the amount of content that we provided to the students so as not to overwhelm them. However, in future deliveries of the course, we will find ways to include additional source material to address this concern.

Students struggled to adopt design behaviors that misaligned with their prior experiences. As undergraduate students, the senior cohort often participated in courses that encouraged them to learn and apply specific design approaches to clearly defined design problems. In contrast, the senior design research studio asked students to consider a range of design theories and develop hypotheses for effective courses of action. Although common at the graduate level, this form of inquiry was foreign to the senior cohort. The inability to align current and prior design education experiences caused the students to have difficulty grasping the relevance of course activities.

Similarly, students spent most of the first half of the term working in teams of six on mapping and diagramming tasks that aimed to aid their understanding and practice of Transition Design. Several students expressed a frustration in the lack of making that took place in the course, which negatively impacted their motivation to fully engage in its activities. This observation indicated the students' narrow definition of making in design, as we had 
believed that all of the activities that they performed were a form of making common in design practice.

Lastly, although the students were able to grasp the fundamentals of service design and design for social innovation relatively easily, applying the methods that we practiced in class using small-scale challenges to their Transition Design work that focused on wicked problems situated in Pittsburgh proved to be difficult. The students seemed conflicted in maintaining the mindset that their work should solve an immediate problem versus shifting their view of design to planting seeds that catalyze systems-level change over a long period of time. We continually discussed their stumbling blocks and referred to their work as interventions to help them adopt a design posture and mindset that facilitates effective work in Transition Design.

\section{Ideas for Improvement}

The discoveries that we gleaned while teaching the Design Research Studio informed changes in planning that were made each week. We believe that it is critical for necessary shifts to occur in the course, as they show students the importance of being agile, empathetic, responsive, and transparent when working in Transition Design. Nonetheless, some challenges were too large for us to address immediately. Therefore, we have begun to brainstorm ways of combatting current obstacles in future manifestations of the course.

Explicitly seed Transition Design approaches earlier in the undergraduate curriculum. We believe it would be beneficial for design courses that precede the Design Research Studio to highlight approaches that are relevant to Transition Design as a means of aiding students' deep dive into the topic during their senior year of study. For example, drawing students' attention to collaborative mapping as a form of making and describing the benefits of designing as a means of speculating rather than solving problems would help students more easily adopt the mindset and posture that is pertinent to the study and practice of Transition Design. Similarly, students noted the benefits of design studies courses that they had taken in prior years, which focused on cultures, systems, and futures, in aiding their current thinking in Transition Design.

Build a comprehensive repository of materials in Transition Design, service design, and design for social innovation. Several times throughout the course, we realized the importance of providing students with a range of readings relevant to the course content. In an attempt to not overwhelm the students, we introduced them to a few texts each week. However, as the term progressed, we discovered that the modest sampling failed to introduce students to a diverse set of perspectives. In the future, we plan to give students a list of required and recommended readings that includes short descriptions of how they relate to one another. The nature of course activities also highlighted a need for case studies situated in the context of Transition Design, service design, and design for social innovation. We anticipate that these readings will help students to understand the application of the theories we discuss, describing the characteristics of each area of design focus, and guiding them through similar processes. 
Gather a body of data on local Transition Design-topic stakeholders for students to study. Wanting to adhere to the ethical obligation to do no harm in communities by not taking advantage of stakeholders for research purposes, we sought alternative ways of providing students with pertinent information. In looking to practices in the field, we found that anthropologists rather than designers gather information from a large sampling of stakeholders, which designers then use to inform the direction of their interventions. Although working directly with stakeholders creates a level of empathy that cannot be achieved by reviewing interview transcripts, this approach would give students a broad sampling of stakeholder input, which they cannot achieve by working with a few members of stakeholder groups. As a result, we plan to build a body of data that students can use to ground their projects in subsequent deliveries of the course.

Continually connect course content to a broader context and practice of design. Despite having built a mental model for the course that illustrates the connections between elements of course content, we inadvertently focused the students' attention on immediate tasks without reference to how they were situated within the broader context of Transition Design. As a result, students struggled to see the relevance of tasks and the connections among them. Thus, we plan to build time for discussing and visualizing the connectedness of course content into the curriculum. Moreover, although we ask students to reflect on course activities and write about their thoughts, we believe students would benefit from well-articulated prompts that direct their attention and aid their development of a mental model for all of the course content.

\section{Part II: Doctoral Student Workshops as Transition Design Research}

Transition Design is bound up in doctoral design research, practice, and teaching. Doctoral students not only read and synthesize foundational texts for Transition Design but they also apply the theories in practice-based design research. That is, the teaching and research of Transition Design takes place through design research: through direct engagements with constituents and communities, in workshops that serve as test beds for Transition Design research, and as a means to test out and evaluate design methods.

Carnegie Mellon has two doctoral programs in the School of Design: a traditional PhD (PhD in Transition Design) and a non-residential, practice-based Doctorate of Design (DDes) program (Professional Doctorate). PhD students, who are mostly residential, pursue a four-year degree that culminates in a dissertation. DDes students are non-residential and participate in a three-year program: they remain in their companies and practices while pursuing their research remotely and attend two to three intensives a year on campus. The DDes provides students an opportunity for career-pivoting work, with a curriculum informed by Transition Design, and the externalization of research in a practical manner (such as in non-academic workshops and community engagements).

In this section, we will look at workshops as design research, some of the findings that doctoral students at Carnegie Mellon have discovered in using these practices, and the broader implications for Transition Design practice. Serving as lenses into the workshops, 
we introduce three doctoral students at Carnegie Mellon: Dimeji Onafuwa, Deepa Butoliya, and Alex Wright. Onafuwa and Butoliya are final year PhD students, and Wright is a Doctorate of Design student (in the three-year, non-residential, practice-based doctoral program). Each of them uses workshops in different ways in their practices, leading to different findings in and through the process.

\section{Three Students, Three Workshop Approaches}

Dimeji Onafuwa is studying practices around the commons and cooperative platforms: his research probes how "Elinor Ostrom's design principles of commoning serve as a foundation for exploring new approaches to user experience on platforms". He applies these questions to two domains: tenancy and data, asking if and how housing tenancy might be viewed as a commons and whether there is a possibility of a "datashed" being a commons for data sharing. Onafuwa built a theoretical framework for his topic in his first year, while working on an app for tenants in Pittsburgh. From the learnings of that project, he later engaged with the Portland Tenants Union and with Intel Research on data sharing and datasheds. He has held workshops in which he developed pattern cards, inspired by Christopher Alexander's pattern languages and by Yoruba aesthetic and narrative principles in storytelling, which explored roles and patterns within the new commons. Figures 15 and 16 show the front and back of a Dilemma card and Figure 17 shows one of eight Role cards (the Town Crier) used in Onafuwa's workshop. Figure 18 is one of the patterns he developed.

Deepa Butoliya's work is in the area of speculative critical design in the Global South, with a focus on what she terms "critical jugaad". She takes the Hindu-language word "jugaad", which refers to ad hoc, make-do solutions with at-hand materials, juxtaposing it with speculative design practices. She co-curated an exhibition called Climactic: Post-Normal Design that opened in November 2016. In addition to the selected global work displayed in the exhibition, undergraduate students in her Critical Speculative Design class designed pieces for the exhibition, and she organized and led workshops during the exhibition run that engaged participants in its content. Shown here is an example of critical jugaad that she displayed in the exhibition: a gas mask, constructed out of ready-at-hand materials (See Figure 19).

Alex Wright, senior director of user experience at Etsy, is a DDes student whose focus is on regenerative user experience (UX) design. He is developing workshops and a curriculum that encourages fellow designers to reframe their practices in more sustainable terms. He is currently teaching a class on futuring at Etsy throughout the fall 2017 term that is open to all Etsy employees, not just designers. The output of this research will be a curriculum design for professional interaction/UX designers and professional doctoral students -potentially also for the Doctorate of Design program itself. Wright works with both internal and external constituents. In his workshops, Wright finds he acts as a translator, bridging the interests of his non-academic audiences while encouraging them to explore longerterm concerns and a more progressive vision of the future. In March 2017, he held two workshops in Pittsburgh in conjunction with Good Work Institute (formerly Etsy.org). In the first workshop -"Purposeful Work"- Wright and Good Work Institute managing di- 
rector Erica Dorn guided Carnegie Mellon students in mapping personal values to future career plans: Figure 20 shows how one student selected values that were important to her. In the second workshop - "THINK Good"- Wright, Dorn, and Carnegie Mellon Professor Kristin Hughes engaged local entrepreneurs, creatives, and government participants in a conversation around resources and ecosystems, centered on Ethan Roland's eight forms of capital (intellectual, social, spiritual, material, financial, experiential, cultural, and living) (2011). Figure 21 shows one sketch by a participant of the relationship of the eight forms of capital to their small business and their life.

\section{Learning from Workshops}

Through the workshops that they designed, Onafuwa, Butoliya, and Wright expand the boundaries of Transition Design and Transition Design practices. They have learned several lessons in reflection on the process. We summarize some of them here.

Participants begin to think big on shared terrain. Workshops open participants to new experiences and ways of learning. "At a high level, what resonates is the appeal to a bigger vision - people yearn for that, they're hungry for it". Wright says about the impact of the workshops he leads. "People feel trapped in their boxes but want to think in a broader way. They're seeking the interconnections at a systems level" (A. G. Wright, personal communication, October 17, 2017). Wright helps guide his attendees in envisioning a progressive vision of the future. However, he finds that workshops such as these are successful when attendees hold points of commonality: fellow students on the cusp of new careers, for instance, or colleagues at Etsy. In Butoliya's workshops, attendees work with their hands to create their own examples of jugaad, using at-hand materials to build masks. In this experiential learning activity, participants begin to understand what it is to find jugaad and begin to grasp it as a worldview.

The diversity of audiences requires workshop content to be tailored and translated. The audience of Transition Design workshops varies widely. In the teaching of Transition Design, doctoral students may thus be teaching students of different levels and backgrounds, including but not limited to Carnegie Mellon students at the undergraduate and master's level (as discussed previously); executives and stakeholders within organizations; colleagues within their own companies; their companies' customers or constituents (such as participants in social innovation efforts); fellow design scholars; and members of local communities with whom a doctoral student is engaged in research. With that the case, Transition Design language might be an obstacle for people who are career-focused and don't typically think beyond what they're doing on a day-to-day basis in their jobs and businesses.

"You're learning about yourself as a designer". Mindset and posture are foundational elements in Transition Design, in which the designer or participant confronts their worldview and may find that it changes in the process. For doctoral students like Onafuwa, Transition Design is less about following methods and more about developing who he is as a designer. Designers in Transition Design practice, foster, steward, and navigate a varied set 


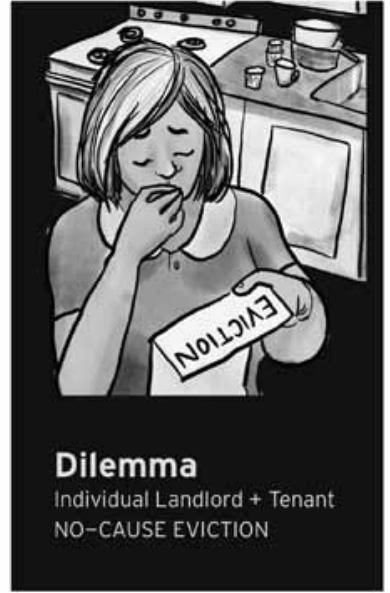

Figure 15.

\section{Dilemma}

Individual Landlord + Tenant

How might we negotiate a no-cause eviction

Janet is a single mom. She rents an apartment from Jabe, a landlord with multiple properties in Portland. Rent payments and rental upgrades were discussed upfront but never codified in a lease. After making numerous consistent payments, Janet finds out through an eviction letter that she needed to vacate the house soon.

Use the cards to negotiate the situation, is there any recourse?

How might we use stories or data to change the situation to one that is favorable for

1. Landlord 2. Tenant 3. Both

Figure 16.

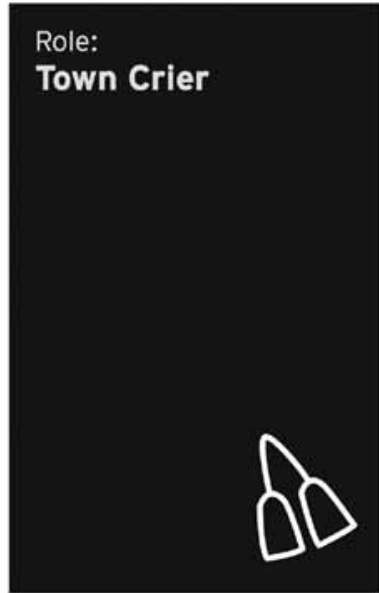

\section{Role:}

\section{Town Crier}

Town criers existed in precolonial Nigeria to circulate information and call the villagers to meetings at the village square or the Baale's (chief) residence. A commoning designer serves the role of a town crier. which is to create conditions for participants to be able to gather.

\section{Questions}

Mow might a sesigner serve as a tom crier on

piatlorm?

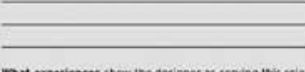

What experiences show the designer as sening this roie

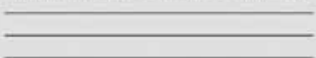

Figure 17.

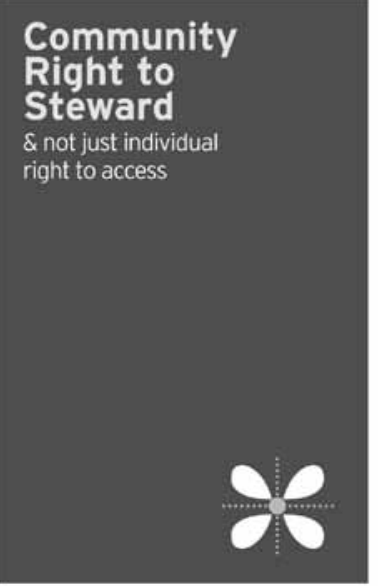

\section{Community Right to Steward}

How might a community serve as an ally to its stakehoiders?

Why? Aceess and stewerestip in commons oese

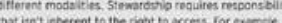
Goth a hurter and a soidier have diterent andis of rempons bility st wes as ieveis of accountability. Questions Mow might s pistorm attort the use of a commen
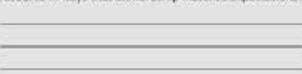

What experiences enenoilv transter of tremardive nights to communtien?

Figure 18.

Figures 15-17. PhD candidate Dimeji Onafuwa created pattern cards, which were inspired by Christopher Alexander's pattern languages and by Yoruba aesthetic and narrative principles in storytelling. He used them in workshops to explore roles and patterns within the new commons. Figure 18. One of the patterns that Onafuwa developed. 


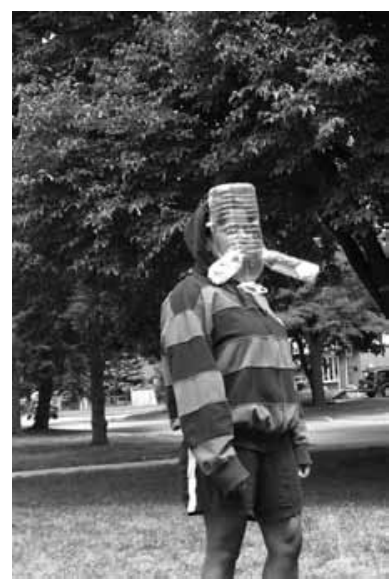

Figure 19.

Figure 19. In an exhibition called Climactic: Post-Normal Design, PhD candidate Deepa Butoliya shows an example of critical jugaad. It includes a gas mask, constructed out of ready-at-hand materials. Figure 20. A participant in a workshop conducted by DDes candidate Alex Wright and Good Work Institute managing director Erica Dorn maps her personal values to career plans. Figure 21. A participant sketched the relationship of the eight forms of capital to their small business and their life during the "THINK Good" workshop conducted by DDes candidate Alex Wright,

Good Work Institute managing director Erica Dorn, and Carnegie Mellon Professor Kristin Hughes.

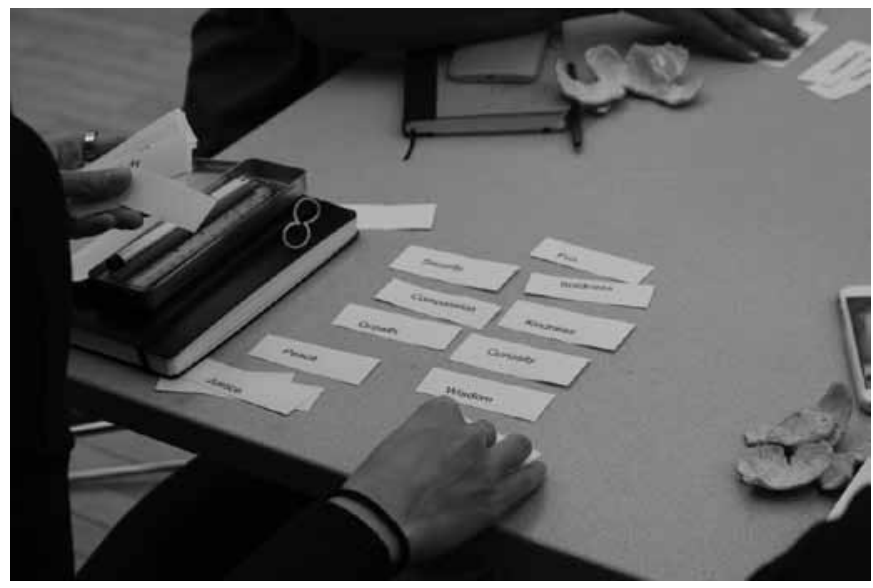

Figure 20.

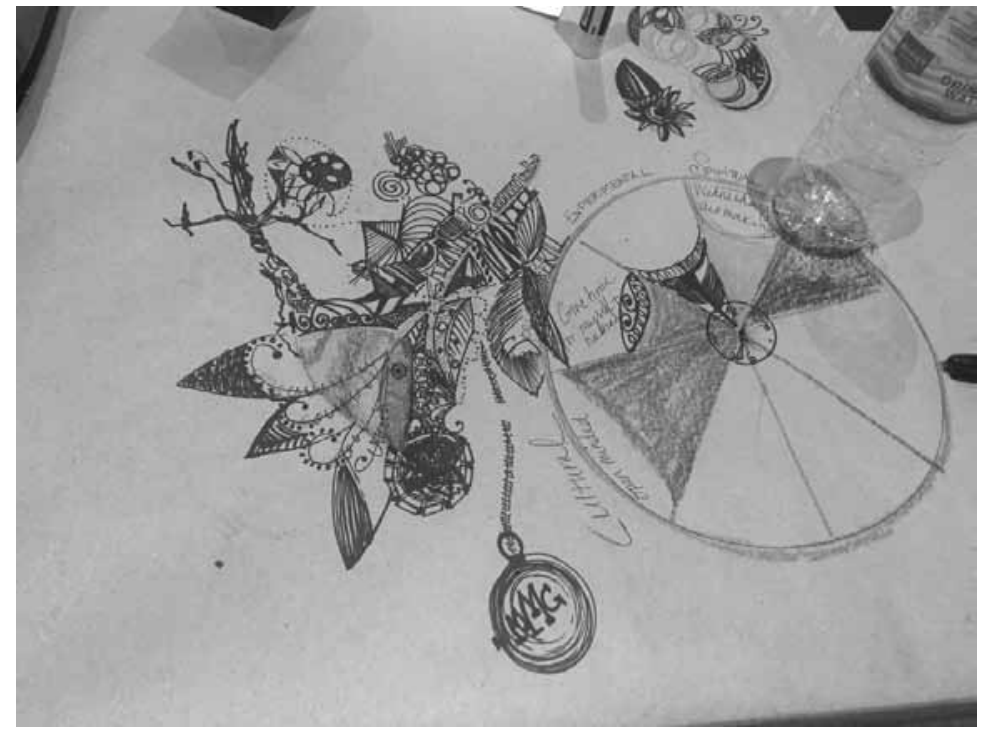

Figure 21. 
of relationships with stakeholders who often don't come to consensus with one another. "I learned that the importance is not that it's empowering and democratizing but an agreement to move forward," Onafuwa said (personal communication, O. Onafuwa, October 17, 2017). "You can't negotiate yourself out of those problems, you just can't". The implications of this position for design are important: instead of design being a process that results in a finished product or service, the designer becomes a weaver of relationships in open-ended problems that are too complex to solve. The designer's ability to reflect is vital.

The practice of Transition Design functions as a set of nonlinear processes. Transition Design requires organizational processes and methods of synthesis that are non-linear. In designing workshops on the commons, Onafuwa started with mapping organizational tools for participants that were linear in nature. Two tools, the social design pathways matrix developed by the Winterhouse Institute (2017) and a linear continuum for commons depletion and regeneration that he developed, account for neither the complexity of the commons nor, more broadly, of transitions. He found that they did not offer an adequate model for the multiplicity of factors within Transition Design. When Onafuwa used social design pathways in the "Design for Social Innovation" course (co-taught with Silvia Mata-Marin at Carnegie Mellon in 2017), he noted that, "Transitions don't fit into those squares". Instead, transitions take place beyond what the squares represent and take into account more factors. Similarly, he found that the continuum he created for a workshop on commons depletion and regeneration did not reflect the richness of factors that arose: what is utilitarian, and what should be stewarded (cared for and protected)? How do the shifts between depletion and regeneration work? "It's not as linear [as the model] -it's messy. Commoning occurs in the shifting between all of those things- it's very hard to think of it in terms of a linear timescale," Onafuwa said. "It was brought to our attention that this model was very problematic to describe something related to transitions. It's not an ordered or practical process. It's messy" (personal communication, O. Onafuwa, October 17, 2017).

Designing for transitions requires designers to color outside the lines. At the doctoral level, we might best be learning that Transition Design requires us to color outside the lines. Just as we codify certain tools and processes to carry out with undergraduates, graduate students, and workshop participants, doctoral researchers push the boundaries of these methods, discover where they bend and break, and develop new methods. They reach out into different subject areas, such as sociology, economics, and data analytics, to inform their research. The learnings of the doctoral students may also challenge what and how we teach Transition Design to undergraduates and master's students at Carnegie Mellon. Rather than viewing curricular revisions in a negative light, we see the evolving process as appropriate for the emerging discipline of Transition Design that grows out of teaching and learning practices in higher education. 


\section{Teaching and Learning Transition Design: Some Conclusions}

Given that Transition Design is in its infancy, we are developing curricula based on emerging theories, borrowing relevant approaches from other disciplines, and learning while doing. Although we have outlined practices that we have found effective and described discoveries we have made, many questions have arisen that we believe serve as opportunities for improving Transition Design curricula.

\section{See Teaching and Learning about Transition Design as a Set of Feedback Loops}

Our students have provided us with insights regarding the teaching of Transition Design that we had not foreseen. While some of their feedback reveals an anxiety for a new way of studying and practicing design, many of their comments describe successes or challenges in working with specific frameworks and obstacles they encounter when working with different teams of people over various amounts of time. We believe it is critical to build opportunities for feedback loops in educational settings to aid the critical review of teaching approaches and inform appropriate revisions.

\section{Create New Tools for Transition Design Practice}

We have utilized approaches developed by adjacent disciplines that have been identified as having potential in aiding the teaching, practice, and research of Transition Design. Nonetheless, the application of many of these methods indicates that although they may hold merit, they require improvements in order to function effectively. Our students have identified problems with existing frameworks and are brainstorming ways of revising or re-envisioning them to make them highly appropriate and useful to the tasks they encounter in Transition Design.

\section{Develop Ethical Approaches for Teaching Transition Design}

Whether learning Transition Design methods as a fourth-year undergraduate student in the context of a design research studio or running Transition Design workshops as a doctoral student, the issue of ethical engagement with the public is always at the forefront of curricular discussions. Wicked problems are symptoms of other problems, and to engage in any aspect of them is to intercede in the problem itself, which produces an ethical dilemma for teaching. Do we use a hypothetical context to teach students methods, void of interaction with stakeholders, or do we strive to build relationships with community groups without knowing if the development of a long-term relationship is realizable? Both approaches are problematic. Thus, there is a need for new approaches that help students understand the contexts of Transition Design in which they are working that are effective and ethical. 


\section{Seed and Catalyze Systems-Level Change through All Areas of Design}

Despite the challenges we encounter in developing teaching of Transition Design, we believe the integration of this new form of design is critical to the success of our students as they embark on lifelong careers in various areas of design. Our doctoral students are focused on researching Transition Design and are directly engaged with the advancement of Transition Design practice. The new curricular methods they develop are directly related to these endeavors. However, for our undergraduate and graduate students, the practice of Transition Design may seem unrelated to their post-undergraduate careers. Nonetheless, we are confident that by exposing our undergraduate students -who are aiming to design products, communications, and environments in the near future- to longer design futures, we are teaching them to be mindful about the long-term consequences of their actions as designers and the materials that they use.

\section{Summary}

In summary, we seek to educate the next generation of designers in a manner that empowers them to seed and catalyze positive systems-level change in design. In this paper, we outlined our endeavors in the context of an undergraduate design research studio and in the work our doctoral students do through the workshops they hold, and we offer evidence of our successes and challenges. Also interwoven into the analysis of our teaching practice are our reflections as researchers and educators ourselves. The activity of teaching and learning as a symbiotic process has facilitated a shift in our own mindset and posture as designers, educators, and researchers.

\section{References}

Candy, S. (2010). The futures of everyday life: Politics and the design of experiential scenarios (Doctoral dissertation) University of Hawaii, Manoa.

Capra, F. (1983). The turning point: Science, society, and the rising culture. New York, NY: Bantam.

Capra, F. (1997). The web of life: A new scientific understanding of living systems. New York, NY: Anchor.

Curry, A., \& Hodgson, A. (2008). Seeing in multiple horizons: connecting futures to strategy. Journal of Futures Studies, 13(1), 1-20.

Irwin, T. (2015). Transition Design: A proposal for a new area of design practice, study, and research. Design and Culture, 72, 229-246.

Kossoff, G., Tonkinwise, C., \& Irwin, T. (2015). Transition Design: The importance of everyday life and lifestyles as a leverage point for sustainability transitions. Retrieved from https://www.academia.edu/15403946/Transition_Design_The_Importance_of_Everyday _Life_and_Lifestyles_as_a_Leverage_Point_for_Sustainability_Transitions_presented_ at_the_STRN_Conference_2015_Sussex_ 
Manzini, E. (2009). A cosmopolitan localism: Prospects for a sustainable local development and the possible role of design. In H. Clark and D. Brody (Eds), Design Studies: A Reader (pp. 448). New York, NY: Berg.

Max-Neef, M. A. (1991). Human scale development conception application and further reflections. New York, NY: Apex Press.

Meadows, D. (1999). Leverage points: Places to intervene in a system. The Sustainability Institute, 3, pp. 78-84.

Phills, Jr., J. A., Deiglmeier, K., \& Miller, D. T. (2008). Rediscovering social innovation. Stanford Social Innovation Review. Retrieved from https://ssir.org/articles/entry/redis covering_social_innovation

Roland, E. C. (2011). Eight forms of capital. Permaculture, (68), 58-61. Retrieved from http://appleseedpermaculture.com/wpcontent/uploads/2011/04/8_Forms_of_Capital _PM68.pdf

Rittel, H. W. J., \& Webber, M. M. (1973). Dilemmas in a general theory of planning. Policy Sciences, 42, 155-169.

School of Design at Carnegie Mellon University. (n.d.). PhD in Transition Design. Retrieved from https://design.cmu.edu/content/phd-transition-design

School of Design at Carnegie Mellon University. (n.d.). Professional Doctorate. Retrieved from https://design.cmu.edu/content/professional-doctorate

Social Design Pathways (2017). Retrieved from http://www.socialdesignpathways.com/ how-to-use/

Thomas, T., \& Leber, B. (2016). 6 key takeaways from the global service jam. Maya Design Blog. Retrieved from http://maya.com/blog/pittsburgh-service-jam-2016

Wahl, D. (2017, June 7). The three horizons of innovation and culture change. Retrieved from https://medium.com/@designforsustainability/the-three-horizons-of-innovation-andculture-change-d9681b0e0b0f

Woodhouse, M. B. (1996). Paradigm wars: Worldviews for a new age. Berkeley, CA: Frog Books.

Resumen: Para el desarrollo del Diseño para la Transición, resulta fundamental su base en la Educación Superior. La base teórica que informa la práctica del Diseño para la Transición se desarrolla a partir de un proceso emergente compuesto de hipótesis, teoría y pruebas en entornos educativos. Estos enfoques, que se centran en abordar desafíos específicos, complejos y basados en la localización, deben adaptarse para abordar la naturaleza de contextos específicos y el aprendizaje variado de las cohortes de alumnos y sus respectivas necesidades. Este documento argumenta la importancia y la integración cuidadosa del Diseño para la Transición en la educación de diseño, e introduce un plan de estudios para estudiantes de diseño de pregrado y doctorado. Describe los métodos y herramientas que se utilizan en nuestra enseñanza, describe los éxitos, identifica los desafíos, presenta ideas para mejorar y propone oportunidades para el desarrollo.

Palabras clave: Diseño para la Transición - educación - currículo - enseñanza - aprendizaje - teoría - práctica. 
Resumo: Para o desenvolvimento do Design para a Transição, é fundamental sua base na Educação Superior. A base teórica que informa a prática do Design para a Transição se desenvolve a partir de um processo emergente formado por hipóteses, teoria e provas em entornos educativos. Estes enfoques, centrados em abordar desafios específicos, complexos e baseados na localização, devem adaptar-se para abordar a natureza de contextos específicos e a aprendizagem variada das coortes de estudantes e suas respectivas necessidades. Este trabalho argumenta a importância e a integração cuidadosa do Design para a Transição na educação em design, e introduz um programa de estudos para estudantes de design de graduação e doutorado. Descreve os métodos e ferramentas que se utilizam nosso ensino, descreve os êxitos, identifica os desafios, apresenta ideias para melhorar y propõe oportunidades para o desenvolvimento.

Palavras chave: Design para a Transição - educação - currículo - ensino - aprendizagem - teoria - prática. 